\title{
SAN MIGUEL DEL MILAGRO
}

\author{
$\mathbf{P} \bigcirc \mathbf{R}$ \\ JOSE ROJAS GARCIDUENAS
}

"F $\mathrm{N}$ el lugar de San Bernabé, Colonia del Curato de Santa Maria Nativi-

E tas, llendo en una procesión un indio... que se llamaba Diego Lázaro de San Francisco, se le aparreció el Soberano Arcángel San Miguel..." dice en su narración el Padre Florencia, S. J. Esta aparición ocurrió el año de 1631, dando origen a un santuario llamado de San Miguel del Milagro en el hoy Estado de Tlaxcaia.

E1 Lic. don Pedro Salmerón fué el primero en registrar la noticia del prodigio, así como el culto que suscitó y los primeros intentos de construir el santuario, en un relato de la aparición cuya copia existe en el Archivo General de la Nación, entre los papeles de don Lorenzo Boturini. Más tarde, el Padre Nieremberg comentó de nuevo el milagro y, finalmente, hacia 1692 se imprimió en Sevilla la "Narración de la Maravillosa aparición que hizo el Arcángel San Miguel", escrita por el Padre Florencia S. J., por orden del Illmo. señor Fernández de Santa Cruz, y que es el mejor de los tres relatos sobre la tradición y santuario de San Miguel del Milagro. Posteriormente han tratado el mismo asunto diversos autores, como lo hace don Genaro Garcia en su biografía de don Juan de Palafox y, par último, en el nú- 
mero 51 de la revista "Hoy", en febrero de 1938, Eduardo Enrique Rios publicó, sobre dicho tema, un artículo acompañado de varias fotografías del santuario.

Todos los cronistas refieren, con mayor o menor amplitud, cómo el año de 1631 se apareció el Arcángel San Miguel al indio Diego Lázaro, revelándole que en un sitio próximo, en el fondo de una quebrada del cerro, se encontraba una fuente de agua santa o milagrosa que tenía virtud de sanar a los enfermos. Diego Irázaro hizo tal revelación del conocimiento de las autoridades civiles y eclesiásticas $y$, tras de algunos tropiezos y contrariedades, el Illmo. señor don Gutierre Bernardo de Quirós, entonces Obispo de Puebla, ordenó se iniciaran las averiguaciones correspondientes.

La primera fué diligenciada por don Alonso Herrera, Canónigo de Puebla, el mismo año de la aparición. Después, el Illmo. señor don Juan de Palafox y Mendoza se interesó mucho por el prodigio ocurrido en su Dícesis y ordenó una segunda información el año de 1643 , con mayor cuidado $y$ detenimiento que la anterior y abundantes declaraciones y testigos de todis calidades. Una tercera información fué encargada por el Cabildo Sede Vacante, hacia 1675, presidida por el Juez Vicario del Obispado y dos Canónigos del mismo y llevada a efecto por el doctor don José Salazar Varona, quien era entonces Racionero de la Catedral de Puebla.

Desde los primeros dias que sucedieron al milagro, la fuente descubierta fué muty visitada y se empezó a rendir culto alli a San Miguel, mas no fué posible construir desde luego templo alguno, tanto porque lo quebrado del terreno aumentaba mucho el costo de cualquier construcción, como porque aun sin tales dificultades, los pobres recursos de los vecinos no alcanzaban para obras de tanta importancia. Por ello, en un principio, no pudo hacerse más que poner una imagen de San Miguel "en un hueco hecho a mano en la misma quebrada"; poco después se hizo en lo alto de la barranca una pequeña ermita con techumbre de paja y más tarde esa ermita se reconstruyó con mayor solidez, poniéndiole su techo de vigas y terrado, pero ya no en lo alto sino en el fondo de la propia bartanca, en el mismo lugar del manantial. Por entonces tampoco el pozo del agua santa había sido arreglado y se encontraba casi en su estado primitivo, sólo que cada vez aumentaba su diámetro por la tierra que constantemente le extraían y la cual, junto con la propia agua, era aplicada a los enfermos. Cuando la ermita se reconstruyó abajo dei cerro, quedó la fuente dentro de ella "arrimada al altar del Santo 
-dice Salmerón-, cubierta con una como puerta levadiza, de suerte que el sacerdote que celebraba estaba sobre la fuente..."

El Illmo. señor don Gutierre Bernardo de Quirós había muerto desde 1638 y, para substituirlo, fué designado don Juan de Palafox y Mendoza, quien, a pesar de que llegó a México en 1640, no pudo hacerse cargo de st Diócesis sino tres años más tarde cuando dejó sus puestos de Virrey y Arzobispo de México.

En ese año de 1643 visitó el señor Palafox la ermita de San Miguel y allí dijo misa. Para esçlarecer debidamente lo que la tradición del lugar referia, ordenó hacer otra información, como antes dije, y luego, tomando gran afición por la ermita y por la devoción que el milagro le inspiraba, dispuso la construcción de un templo y el arreglo del lugar, cual convenia a sitio tan favorecido y visitado.

Parece que en el primer proyecto del templo el pozo quedaba dentro de la iglesia, como ya lo estaba en la segunda ermita, pero ese proyecto fué rechazado y se determinó, con mejor sentido, que el pozo quedara fuera y al frente del nuevo templo.

Nada despreciables deben de haber sido los gastos que la nueva construcción ocasionó, pues para realizarla fueron menester obras extraordinarias como rebajar el cerro y terraplenar parte de la barranca; para todo ayudó Palafox ampliamente, ya con dinero de su peculio particular en muy buena parte, y luego con los donativos de algunos eclesiásticos y el producto de la colecta pública que se hizo con autorización del señor don Juan de Mañozca, Arzobispo de México, y del Virrey Conde de Salvatierra. Cuando el templo quedó concluido, el Illmo. señor Palafox lo consagró, celebrando la primera misa que allí se dijo.

Desde un principio la afluencia de peregrinos hizo sentir la necesidad de una hospederia o sitio en que encontrasen abrigo los visitantes y especialmente los enfermos que en gran número acudian. En los primeros años, cuando la ermita estaba en el cerro, los devotos se guarecían en unas cuevas que hicieron en las paredes de la barranca; esas oquedades en el tepetate del cerro eran alojamiento demasiado primitivo e insuficiente y, por ello, cuando se construyó la iglesia, se hicieron también algunas casas de adobe.

Según el relato del Padre Florencia, la construcción de la hospedería corresponde al celo y esfuerzo del Illmo. doctor don Manuel Fernández de Santa Cruz, quien se hizo cargo del Obispado de Puebla en 1687 ; sin em- 
bargo, Florencia reconoce que otras construcciones importantes se hicieron antes del gobierno del señor Santa Cruz y asi cuenta que, durante el episcopado del señor don Diego Ossorio de Esscobar, se construyó "la escaiera de piedra de cantería que baja al patio de la Iglesia", gracias a la munificencia del general don Diego Orejón, prominente vecino de la ciudad de Puebla. En realidad, bien puede afirmarse que la narración del Padre Florencia, S. J., trata un poco superficialniente la obra del señor Palafox en San Miguel del Milagro y, al mismo tiempo, tiende a resaltar lo que hizo el Obispo Santi Cruz, a quien el autor dedica enconiásticamente su libro; así, Florencia no dice que Palafox tuviera en San Miguel un lugar de retiro adonde iba con frectuencia en busca de aislamiento y paz espiritual ; siendo asi que la preferencia demostrada por Palafox al agreste y devoto sitio de la aparición fué y es bíen conocida. Don Genaro García habló de ella diciendo: "Objeto especial de la piedad religiosa de Palafox fué una humilde ermita dedicada al Arcángel San Miguel en el pueblo de San Bernabé, de la jurisdicción de Santa Maria Nativitas'. Aún se conserva la tradición viva y allí se encuentra una mediana pieza que, hasta hoy, es llamada "el cuarto del Venerable", donde guardan como reliquias diversos objetos que fueron del señor Obispo $\mathrm{Pa}-$ lafox. El silencio que sobre esto guarda Florencia parece intencionado $y$ sugiere la sospecha de que tal vez se debió al resentimiento que la Compañia de Jesús conservó, durante mucho tiempo, en contra del santo Obispo que tan enérgicamente luchó por reducir a orden y autoridad a los ensoberluecidos jesuitas de Puebla en el siglo XVII.

Finalmente, y para completar este breve resumen histórico, es preciso mencionar la construcción del aljibe y su correspondiente pila. Muy penosa y molesta resultaba la carencia de agua para uso corriente que se padecia en la hospedería y en las casas que se hicieron a un lado de la iglesia. en al fondo de la cañada, pues no había allí más agua que la del pozo milagroso, la que, naturalmente, no estaba para ser utilizada en los diversos menesteres cle la vida diaria. Para remediar este grave inconveniente se construyó un aljibe que recibía el agua de lluvia escurrida de las vertientes próxinas; pero, estando este depósito muy arriba del cerro, se adicjonó de "un conclucto subterráneo con su llave" que terminaba en una pila de piedra labtada. que al decir de Florencia tuvo un costo de mil pesos, y que fué regalada por el señor don Miguel Raboso de la Plaza, de quien no he podido tener mís datos que el haber sido Alguacil Mayor de Puebla y haher fallecido el año de 1680 en esa ciudad. 
In la actualidad el santuario de San Miguel del Milagro, que sigue siendo visitado por gran número de peregrinos, comprende distintas construcciones de varias épocas y de muy diverso valor artístico.

El templo es el construído por mandato de Palafox en el siglo XVII. Tiene planta de cruz latina, de una sola nave, con cruceros pequeños y bóvedas de lunetos, siguiendo el estilo de la época sin particularidades ni características especiales.

La portada es de cantera gris, con dos cuerpos y un remate, severa y esbelta y presentando los sillares de los extrenos laterales en saliente a manera de enormes dentellones. El primer cuerpo lo ocupa la puerta principal con marco y arquitrabe bartocos y un friso muy sencillo con una cornisa que separa el prinker cuerpo del segundo; éste contiene una gran veritana con marco labrado y un cornisuelo, la ornamentación un poco más recargada que la del marco de la puerta; a los lados se encuentran dos escudos también en piedra: el del lado del Evangelio contiene un Crucifijo sobre un corazón y el lema Anor Meus Crucifixus Est, timbrado con un ángel que sostiene una corona de espinas; al lado de ia Epistola está el blasón con las armas del señor Palafox y Mendoza en la siguiente forma: Escudo cuartelado; en el primer cuartel, dos fajas en campo poblado de nueve cruces; segundo cuartel, tres barras; en el tercero, trece corazones $y$, en el cuarto, tres bastos en barra; timbrado con un ángel que sostiene sobre el escudo una corona de marqués. No están indicados esmaltes ni metales, pero es inoudable que se trata de las armas del Obispo Palafox, atuque la corona de naarqués nos parezca inprocedente, pues aunque su padre fué Marqués de Ariza, la bastardía de don Juan, confimada en los cuarteles segundo y cuarto del blasón mencionado, hizo que el título recayera en su medio hermano, quien fué tercer Marqués de Ariza.

Sobre la ventana del segundo cuerpo, que ilumina el coro de la iglesia, está un gran nicho de medio punto enmarcado por dos pilastras y en él una imagen del Arcángel titular de la iglesia, con espada en la diestra y sin casco.

Rematan la fachada las armas españolas, en escudo cuartelado con castillos $y$ leones pero sin granada, con la corona real y el toisón de oro.

Al nivel de la cornisa de la ventana, a cada lado de la portada, hay unos escudetes invertidos con las inscripciones "año" y "1653", respectivamen- 
te, $y$ un tercer escudete en lo más alto del remate el cual tiene esculpido "MYO".

Sobre el crucero de la iglesia una cúpula de tipo poblano, de media naranja recubierta de azulejos, con cuatro ventanas abiertas en la misma media naranja, sobre las pechinas, y rematada por una linternilla de esbeltas proporciones.

Detrás del altar mayor hay un camarin, que supongo de época posterior a la iglesia, así como otra cúpula sobre el altar mayor, la que notablemente difiere de la cúpula del crucero, ya mencionada. Essta del altar mayor no es de media naranja sino bastante peraltada y se asienta sobre un tambor de regular altura en el cual se abren las ventanas; creo que esta cúpula no puede ser más antigua del siglo XVIII.

En época reciente se añadió al templo un campanario en torre de dos cuerpos y remate, con arcos de medio punto, pilastras jónicas, remates neoclásicos en forma de copas festonadas, etc., todo de pésimo gusto. Peor es todavía la torrecilla del reloj, sobre la portada, hecha de ladrillo y cenento, con la fecha en grandes cifras: 1926, verdaderamente horrible y que vino a estropear la silueta elegante del remate del siglo XVII.

Decoran el interior de la nave dos grandes óleos del siglo XVII sobre asuntos similares al prodigio ocurrido en el lugar, uno de ellos representa la aparición de San Miguel en una cueva del Monte Gargano y, en dicho cuadro, figurado en el Obispo se encuentra el retrato del qute, siendo cura de Santa Maria Nativitas, mandó hacer tal pintura al ser elevado al cargo de Racionero de la Catedral de Puebla.

El púlpito, que tiene fecha de 1708, está fornado por un ángel de tecali, por cariátide, que sostiene la cátedra hecha con las hojas cle un biombo chino, de laca, con dibujos en rojo y oro sobre un fondo negro.

La imagen del Arcángel titular es una escultura de madera, con alas de plata repujada así como la palma que sostiene con la mano izquierda, mientras que con la derecha empuña una larga cruz de metal dorado, tiene casco y cimera con plumas de colores y se encuentra ataviado con rico traje a la manera del siglo XVIII. Tras del altar mayor hay un camariu, al que ya aludi en líneas anteriores, donde se encuentra otra imagen del Arcángel, también de madera, de mucho más movimiento en la actitud y en los paños : ésta del camarin, de menor tamaño que la otra, por tener el cabello rubio es llamada de San Miguel "el Gachupincito" y menos venerada que la imagen 


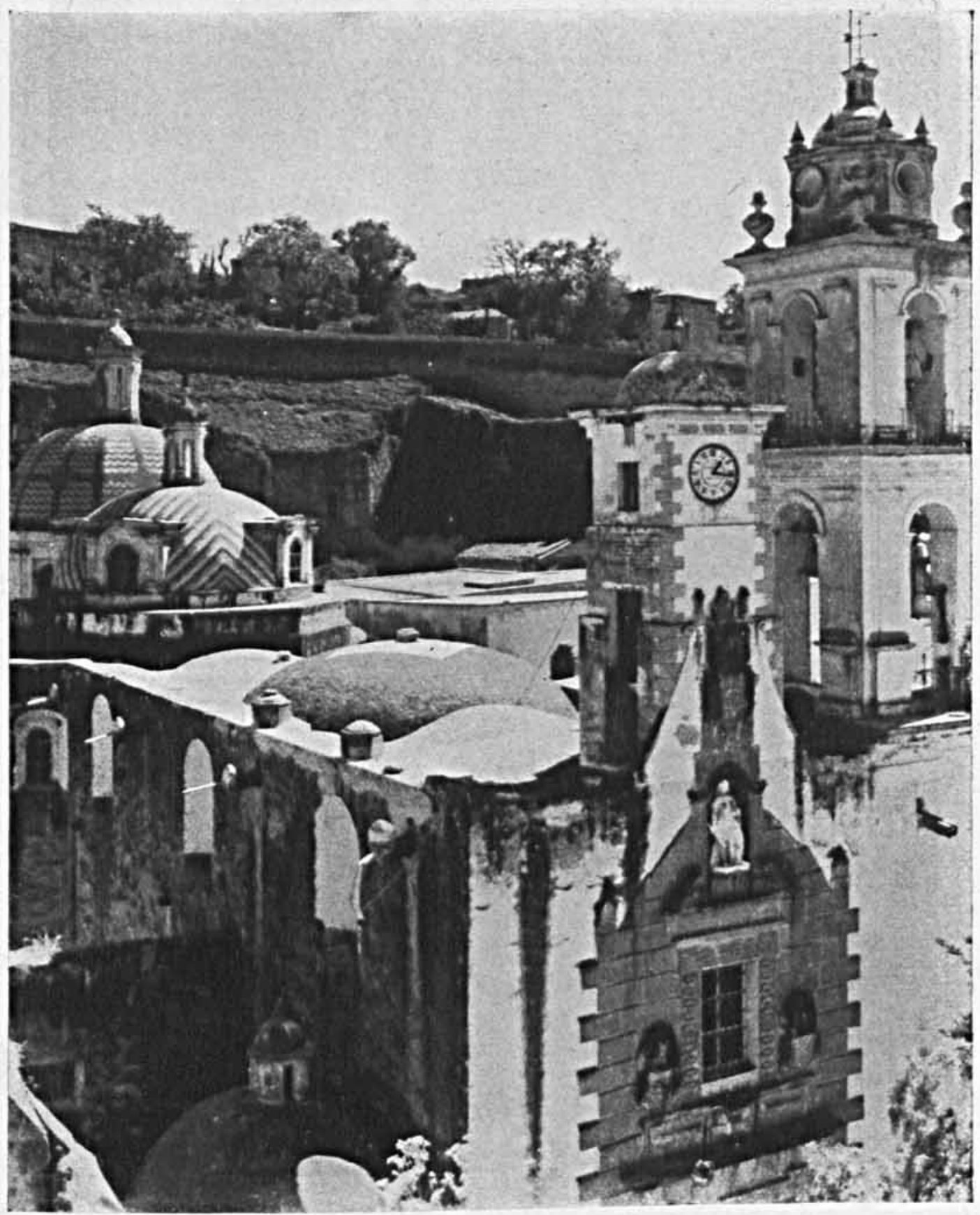

Fot. Diaz.

1 -Vista de conjunto del santuario de San Miguel del Milagro. 


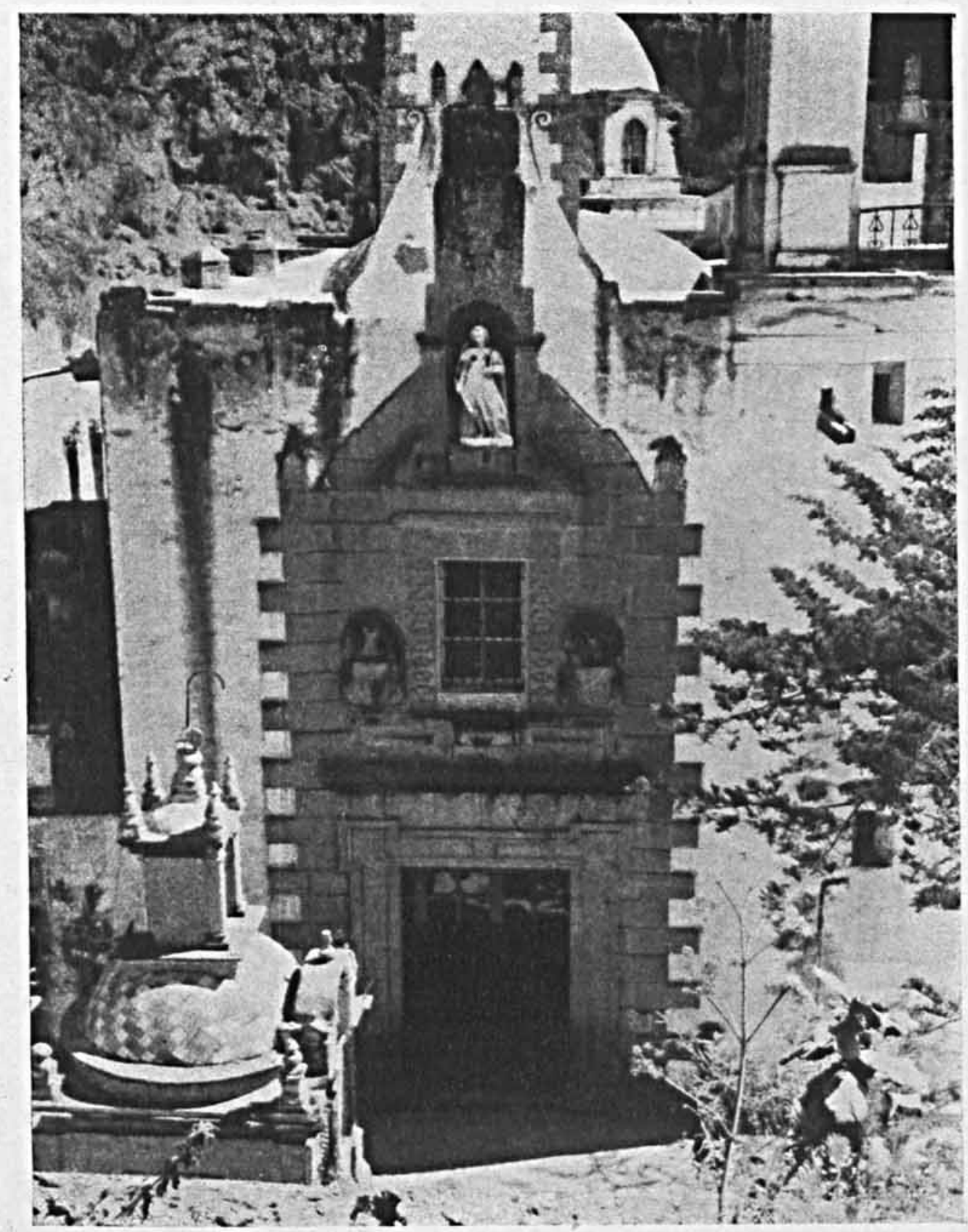

Fot. del autor.

2.- San Miguel del Milagro. Portada de la Iglesia. 


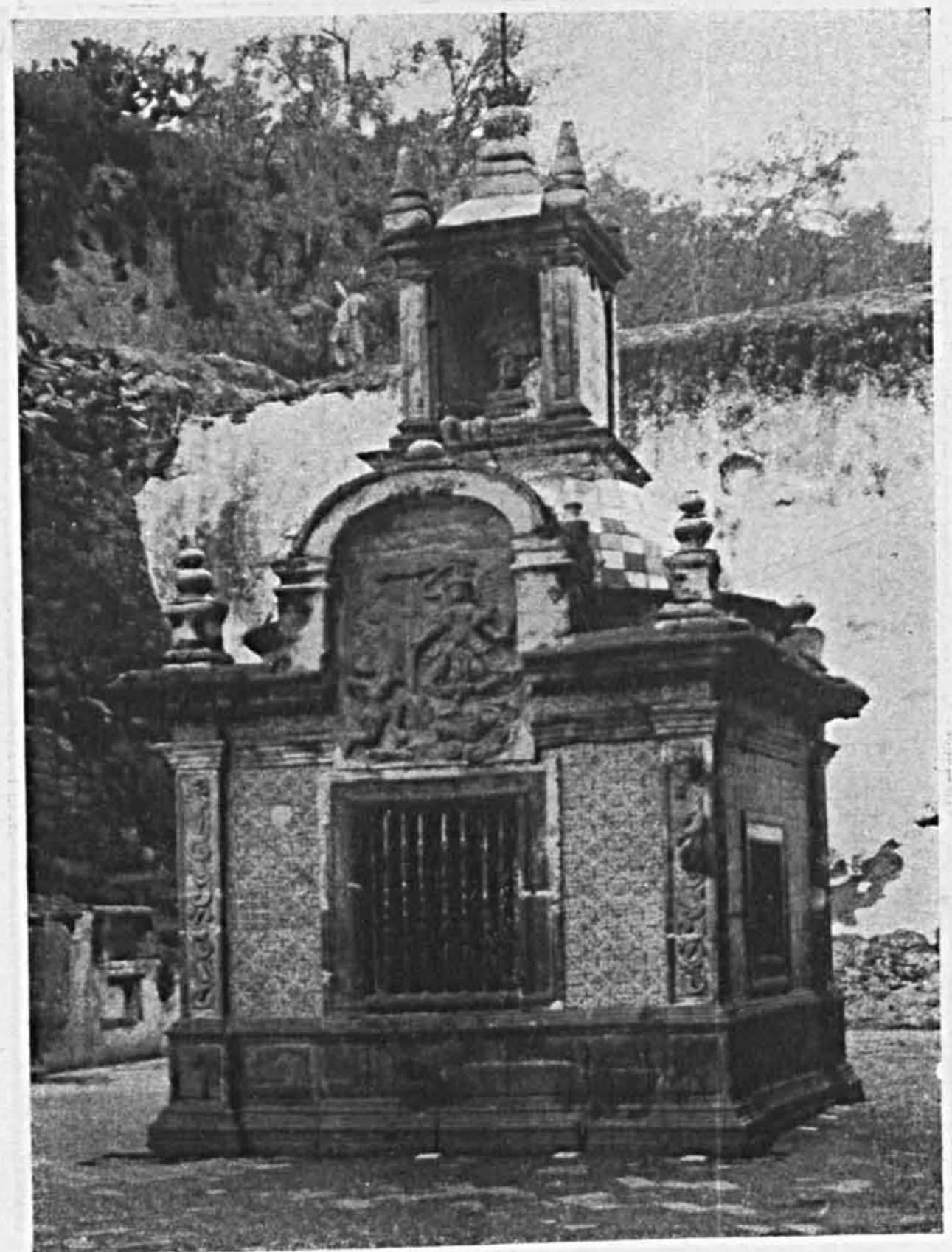

Fot. Luis Márquez.

3.- San Miguel del Milagro. Pozo del agua santa. 


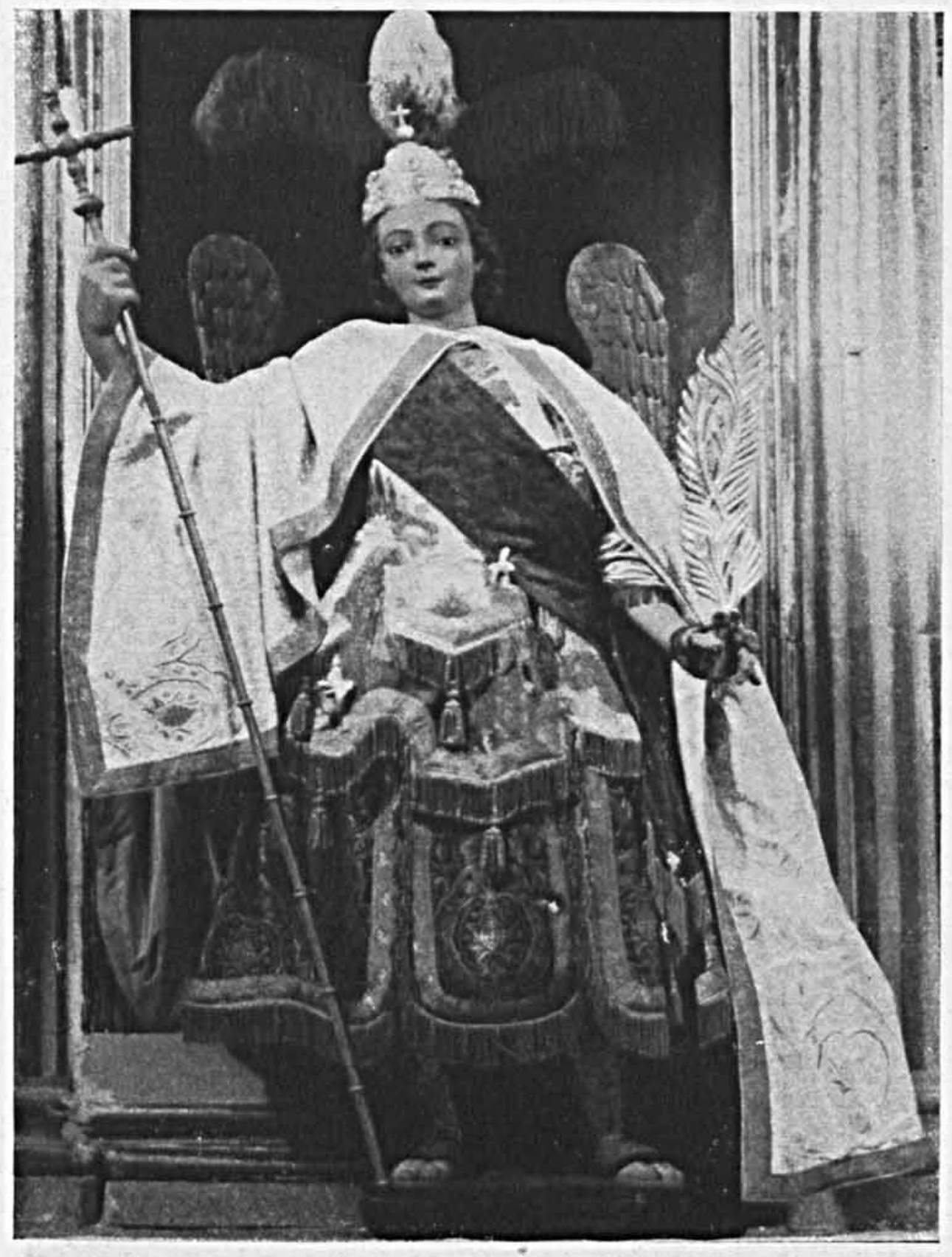

Fot. Luis Márquez.

4.- Imagen del Arcángel San Miguel, venerada en San Miguel del Miiagro. 


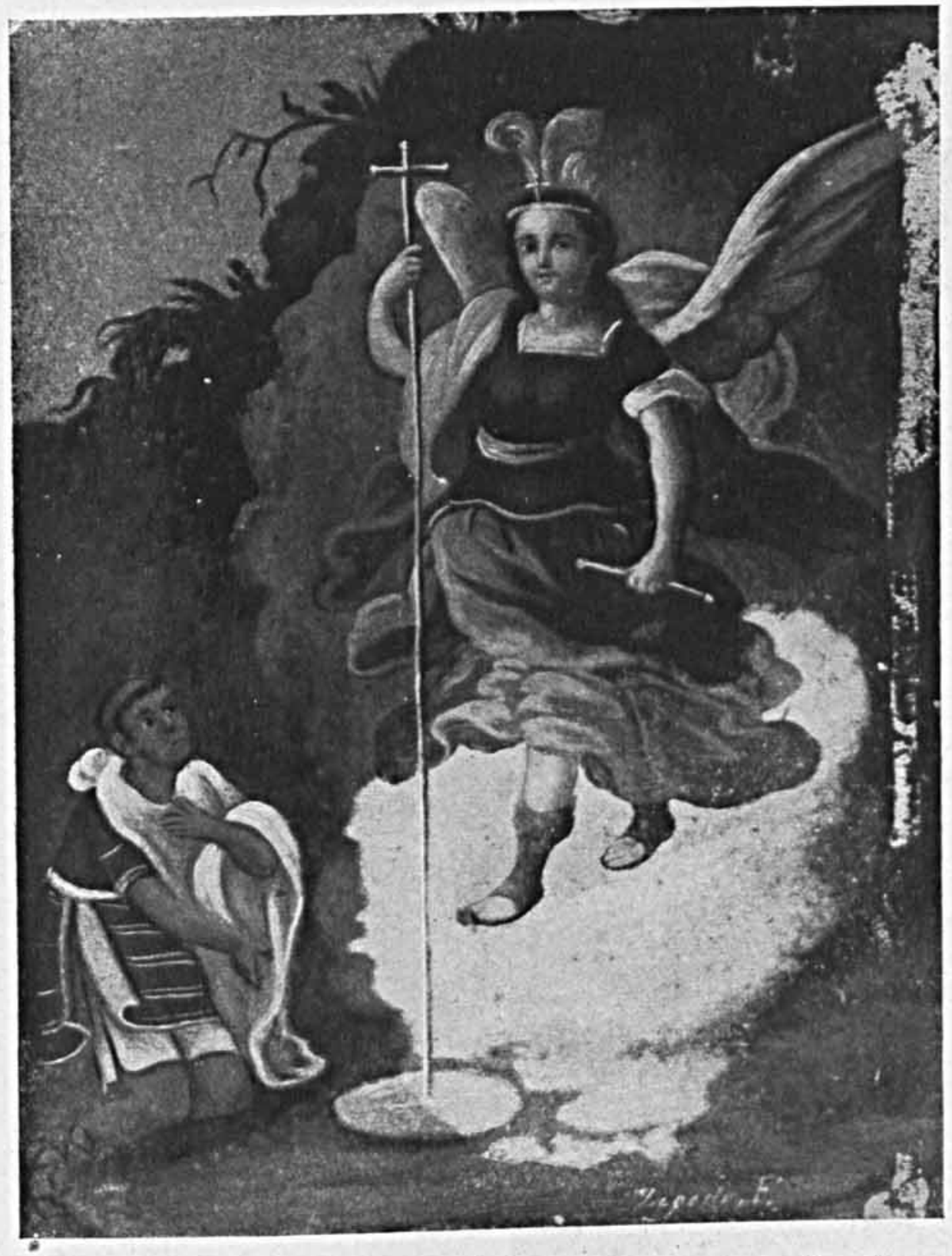

5.- San Miguel del Milagro. Lámina al óleo firmada por Zepeda. Col. M. Toussaint. 


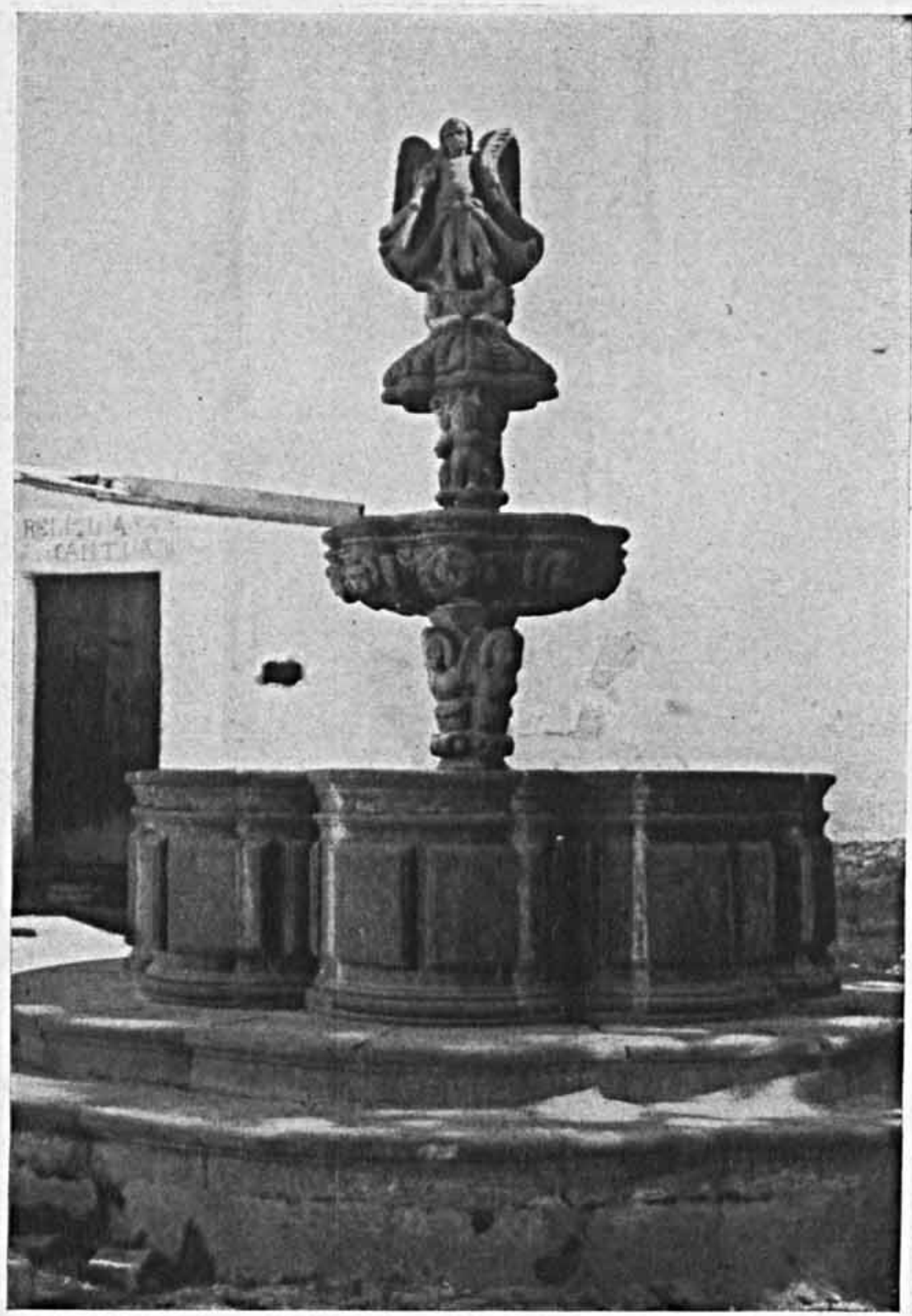

Fot. Diaz.

9.-Fuente en el atrio de San Miguel del Milagro. 
principal del altar mayor, la que es considerada, probablemente, como más nacional.

Entre el altar mayor y el camarín, cubierto por una gran lápida con inscripción latina, se encuentra el sepulcro de Diego Lázaro. Los exvotos que el santuario posee son muy numerosos, y entre ellos hay interesantes ejemplares de pintura popular del siglo XVIII hasta el presente.

Además de la iglesia hay otras construxciones que deben ser mencionadas. Ya hemos hablado de la hospederia construida a fines del siglo XVII. Actualmente se encuentran ahí las oficinas y residencia del señor Presbitero en funciones de rector del santuario. Desde el punto de vista artístico sólo cabe mencionar la magnifica escalinata de piedra que hizo construit el Alcalde Mayor de Puebla don Diego Orejón, en el nismo siglo XVII, la que lleva a un patio alto en uno de cuyos mutros se ostenta, en argamasa, un escudo de la siguiente manera: Cuartelado; primer cuartel, un árbol; en el segundo, una garza sobre una torre; en el tercero, tres tajas; el cuarto, cortado: primero, un león atado a un árbol y, segunto, cinco flores de lis. Acolado a cruz de Alcántara. No hay indicación de metales ni esmaltes: con timbre eclesiástico de sombrero, corclones y borlas de Obispo y ornado con lambrequín y adorno puramente ornamentales. Êl señor don Guillermo Fernández, ha encontrado que tal escudo perteneció al Illmo. Sr. D. Pedro Nogales Dávila, Caballero de Alcántara, que fué Obispo de Puebla en el primer tercio del siglo XVIII.

Ên cuanto a motivos heráldicos en la crnamentación, debe mencionarse otro blasón que se encuentra en el muro de la fachada de la iglesia, a un costado de la portada; el escudo es bastante complicado, advirtiendo desde liego que no están marcados los colores ni los metales, as asi:

Cortado de dos y partido de tres, con escusón sobre el todo.

Primer cuartel: seis barras con bordura de calderos sobre llamas.

Seguî̀ cuartel: una banda; un castillo en el cantón siniestro del jefe (cl cantón diestro de la punta está cubierto por el escusón).

Tercer cuartel : cuatro caras de perfil y una de frente, ésta en el centro con casco y cimera de plumas.

Cuarto cuartel: dos calderos jaquelados, en palo, el cle abajo sobre llamas, bordura jaquelada.

Quinto cuartel: Mantelado. Primero, un león rampante y contornado; segundo, vacío; mantel : león rampante coronado y contornado. 
Sexto cuartel : una banda, en el cantón superior izquierclo dos figuras de aniniales pasantes (que deben ser perros o lobos).

Escusón: en sotuer y con bordura. Primero y cuarto: un caldero jaquelado; segundo y tercero, (la figura es confusa, parece una rama con cinco flores pero es dudosa su representación). Bordura de castillos y leones pasantes.

Acolado a Cruz de Santiago y timbrado con corona que parece ser de ducque.

Esste escudo es indudablemente del siglo XVIII, pues ya tiene la base apuntada. En ni concepto, contiene varios errores heráldicos, lo cual dificulta muclio más su identificación. Sin haber podido averiguar a quién perteneció este blasón ni el motivo de encontrarse en tal lugar, es de suponerse que haya sido de algún benefactor del santuario. Los señores don Guillermo Fernández y don Ignacio del Villar Viltamil stponen que el segundo cuartel, en el ángulo cubierto por el escusón, debió traer un león, en cuyo caso serian armas de Castilla, de la rama bastarda ; el cuarto cuartel, con calderos y bordura, opinan dichos heraldistas sea de Pacheco, casa de los marqueses de Cerralvo y, finalmente, el escusón sobre el todo parece Guzmán.

Acaso buscando entre los santiaguistas que tuvieron relación con San Miguel del Milagro pudiera encontrarse al propietario del blasón referido; en caso semejante sólo tengo noticia del caballero don Diego Orejón y de Soris-aunque seguramente no fué suyo el blasón-, ya mencionado en página anterior como donante de la escalinata de cantería, que fué Alcalde Mayor de Puebla y que ingresó a la Orden de Santiago, en Madrid, el año de 1642.

El pozo de agua milagrosa cuya existencia, según la tradición, fué revelada por el Arcángel a Diego Lázaro, quedó un tiempo fuera de la ermita, conio queda dicho, pero al construir el templo se acordó dejarlo fuera y enfrente del templo; entonces se hizo en torno suyo, para cubrirlo y resguardarlo, una pequeña construcción en forma de capilla cuadrada, con una puerta y tres ventanas. En los ángulos hay pilastras cuadradas con omamentación barroca, sobre bases de cantera gris; en la parte alta de los muros, recubiertos de azulejos poblanos, corre un friso con su cornisa barroca y las pilastras terminan en remates del propio estilo. Cubre la construcción una cúpula pequeña de azulejos y remata en linternilla cuadrada que forma una hornacina donde se aloja otra-imagen del Arcángel. I.as ventanas tienen 
rejas de barrotes fusiformes nuy bien trabajados y sobre la ventana principal, se encuentra un relieve en piedra de la escena de la aparición de San Miguel, teniendo a sus pies a Diego Lázaro de rodillas, todo de un gusto plenamente barroco.

No podrian teminarse estas breves notas sobre San Miguel del Milagro sin mencionar la preciosa fuente de cantera que sirve para recibir el agua recogida en el aljibe del cerro. La pila es de cantera gris con un gran tazón y pilón en el centro, renatado por un San Miguel armado en la diestra y con una palma en la izquierda. El pilón central es típicamente barroco de gran finura ell su ornamentación, tanto en el dibujo como en la ejecución de la misina. sin recargo excesivo, antes gracioso y elegante, pone una nota de refinamiento y finura junto a la severidad de la iglesia y enmedio del paisaje bravio que la rodea. 